\title{
Bone phenotypes in response to gonadotropin misexpression: the role for gonadotropins in postmenopausal osteoporosis
}

\section{Jason P Mansell}

Department of Oral and Dental Sciences, Division of Oral Medicine, University of Bristol Dental School, Lower Maudlin Street, Bristol, BSI 2LY, UK
Correspondence: Jason P Mansell Division of Oral Medicine, University of Bristol Dental School, Lower Maudlin Street, Bristol, BSI 2LY, UK

Tel +44II 79284779

Fax +44 II79299898

Email j.p.mansell@bris.ac.uk
Abstract: Scant attention has been paid to the potential role of gonadotropins in bone tissue homeostasis. The focus on estrogen and estrogen replacement therapy for osteoporosis as far back as the 1940's may account for the paucity of gonadotropin studies in bone biology. It is conceivable that prevailing dogma may have subconsciously steered us away from addressing whether gonadotropins have a place in skeletal physiology. However an examination of bone tissue catabolism in ovariectomized (OVX) and luteinizing hormone-releasing hormone (LHRH) agonist (Zoladex ${ }^{\circledR}$ )-treated rats generated some interesting and conflicting data; Zoladex-treated rats, unlike the OVX group, failed to exhibit increased bone collagen catabolism despite clear evidence for estrogen deficiency. The findings, although controversial, supported the possibility that elevated gonadotropins in the OVX model were in some way accountable for increased bone catabolism. In response to these initial findings further studies were performed to determine if altered LH status may in some way impact on the skeleton To this end an investigation of bone mass and histomorphometry were conducted in LH receptor nullizygous mice and human chorionic gonadotropin (hCG) overexpressing mice. There were clear phenotypic differences; the LH receptor knockout mice displayed reduced bone mass whereas the hCG overexpressing animals had stark increases in bone mass. Much more recently the team of the Mount Sinai Bone Program have made a significant discovery that bone-resorbing osteoclasts express receptors for follicle-stimulating hormone (FSH) and that mice nullizygous for FSH receptor are resistant to bone loss despite severe estrogen deficiency. Details of these fascinating models will be presented together with additional findings that give credence for exploring gonadotropin action on the skeleton as we enter the twilight of this Decade of the Bone and Joint.

Keywords: gonadotropins, bone, osteoblasts, osteoclasts, follicle-stimulating hormone, luteinizing hormone

\section{Estrogen's claim on bone: an historical perspective}

In 1941 Fuller Albright and colleagues were the first to communicate the association of osteoporosis (OP) with the menopause. At the time this important revelation was made it was generally accepted that the menopause was associated with ovarian failure and that estrogen levels declined with the menopause. Since ovarian failure seemed synonymous with increased bone loss it was postulated, as early as the 1940's, that replacement estrogen might prevent OP. Certainly in the past two decades, estrogen, or hormone replacement therapy (HRT), has been an established prophylaxis for OP because it has successfully reduced the extent of bone loss and/or preserved bone mass postmenopause (Lindsay 2004; Stevenson 2005). Although it is generally agreed that estrogen plays a role in skeletal homeostasis the precise mechanism by which it exerts its sparing effect on bone is still not fully understood. To this end a concerted global effort has ensued to identify how estrogen contributes to bone metabolism and to ascertain if the effects of this steroid hormone are direct or otherwise. 
For a considerable time the effects of estrogen on bone were thought to be indirect since receptors for estrogen had not been isolated from bone tissue. The identification of estrogen receptors in human primary osteoblasts and osteoblast-like osteosarcoma cells twenty years ago provided the first indications that a direct effect of estrogen upon bone tissue might be involved (Eriksen et al 1988; Komm et al 1988). Gideon Rodan (1991) proposed that estrogen might exert an anabolic action in bone either directly or via the generation of local growth factors. Early evidence in support of an anabolic action of estrogen in bone came from studies using rat osteoblasts (Ernst et al 1989; Gray 1989) in which type I collagen mRNA expression increased in response to estrogen. However estrogen administration to rats does not stimulate bone formation (Westerlind et al 1993). Also, research conducted in Rigg's group found no direct effect of estrogen on human osteoblast growth and maturation (Keeting et al 1991). Similarly estrogen was without effect on type I collagen protein synthesis in human fetal (Robinson et al 1997) and adult (Mahonen et al 1998) osteoblasts. Although attractive, the possibility that estrogen might elicit a direct anabolic action in mammalian bone is certainly not compelling; estrogen actually inhibits pre-osteoblast proliferation and decreases osteoblast activity (Turner et al 1994) and only modest increases in bone mass have been obtained for mice treated with suprapharmacological doses of the steroid (Samuels et al 1999). Furthermore a dose of $1500 \mu \mathrm{g}$ estrogen/kg murine body weight was unable to induce endocortical bone formation (Bain et al 1993). Given that $5 \mu \mathrm{g}$ estrogen $/ \mathrm{kg}$ is sufficient to saturate the estrogen receptor ligand-binding sites it is highly unlikely that the effect of estrogen on any bone formation is via a "conventional pathway" (Turner 1999). Turner comments that the increased bone mass (more specifically, osteosclerosis) reported by Samuels and colleagues (1999) is attributed to bone marrow toxicity due to the very high circulating estrogen titre. Suffice it to say estrogen does not appear to be a particularly potent factor in the regulation of bone mass; mice nullizygous for either estrogen receptor alpha or beta have normal bone mass, furthermore only modest osteopenia is observed in mice lacking both receptors (Lindberg et al 2001; McCauley et al 2002; Windahl et al 2002).

One other possible influence of estrogen on the skeleton is to inhibit the process of bone resorption by osteoclasts. With over half a century of basic and clinical research conducted after Albright and colleagues made the important connection between estrogen deficiency and OP, Pacifici (1998, 2008) distilled the biological basis of postmenopausal OP down to increased bone-resorbing cytokine production. The miscreants responsible are chiefly interleukin-1 (IL-1) and tumor necrosis factor-alpha (TNF- $\alpha$ ) and their significance to the pathogenesis of postmenopausal OP will become clearer in due course. Most recently Nakamura and colleagues (2007) have provided evidence that estrogen withdrawal may prolong the life span of osteoclasts which in turn might be to the detriment of bone during periods of prolonged estrogen deficiency. In light of the proven efficacy of HRT in preserving bone mass postmenopause it is likely that estrogen dampens the process of bone resorption rather than promoting matrix synthesis.

Menopausal endocrinology is not a simple case of estrogen decline. At the time of Albright's publication in 1941, far less was known about menopausal endocrinology. Although extragonadal factors (primarily from the pituitary) were believed to influence gonadal function Herbert McLean Evans and colleagues only coined the terms folliclestimulating hormone (FSH) and luteinizing hormone (LH) four years prior to Albright's publication (Medvei 1982). Furthermore the association between LH/FSH and estrogen within the ovarian - pituitary axis was not understood and this continued for many years to come. Indeed the dynamic link between estrogen and gonadotropins even escaped Pincus and Kirsch in 1965 (Medvei 1982). It is widely recognized that even modest estrogen withdrawal culminates in a corresponding rise in both LH and FSH from the anterior pituitary. It is particularly noteworthy why investigations into LH/FSH on bone metabolism have not, until quite recently, been considered despite the inverse and inextricable link between circulating estrogen and LH/FSH. It is a genuine possibility that raised gonadotropin levels might participate in bone resorption and contribute to the pathogenesis of postmenopausal OP. A description of how they came to be identified in the context of bone biology and how they might impact upon the skeleton are presented below.

\section{Zoladex versus ovariectomy in the rat; early indications for a role of gonadotropins in stimulating bone loss}

The biochemical composition and metabolism of bone collagen in OP formed the $\mathrm{PhD}$ thesis of the author. Part of the $\mathrm{PhD}$ studies involved the application of the ovariectomized (OVX) rat model, a widely used and accepted experimental tool to study bone in response to estrogen withdrawal (Saville 1969; McOsker and Li 1991; Wronski and Yen 1991). In addition to 
the OVX model, I was keen to explore alternatives to OVX, primarily from a welfare point of view. One particularly attractive alternative to OVX was the application of a depot formulation of the luteinizing hormone-releasing hormone (LHRH) agonist goserelin (Zoladex) that had been shown to last at least one month (Ward et al 1989). Although the LHRH agonist buserelin had been used previously in rats (Goulding and Gold 1989), this required daily injections and therefore constant animal handling, which was something I wanted to avoid.

Total hydroxyproline (Hypro) excretion relative to creatinine clearance was used to monitor collagen catabolism in the OVX and LHRH models on a weekly basis. As expected Hypro excretion rose markedly within the first week of OVX and remained elevated for up to 3 weeks after which it steadily fell to control levels by the sixth week. In marked contrast Zoladex administration led to reduced Hypro excretion which returned to control levels after one month. A second depot likewise resulted in a significant reduction in Hypro excretion, the levels once again rising to controls by week 8. A clear polarization in Hypro excretion was evident; OVX was producing the expected rise in collagen catabolism whereas estrogen deficiency triggered by Zoladex was actually decreasing it. Although the use of Zoladex was employed as an alternative to OVX for the induction of estrogen deficiency, it was particularly interesting to note a very different response of the model to agonist treatment in terms of bone catabolism. Goulding and Gold (1989) had stated that "the degree of osteopenia elicited by OVX and buserelin treatment was similar" and that "administration of buserelin provides a new way of inducing estrogen-deficiency osteopenia in the rat without removing the ovaries". However, their own data do not really give credence to these statements. For example all the urine Hypro analyses for the agonist-treated rats gave lower values than the OVX group. In addition for half of the time points the urine Hypro concentration between controls and agonist treated animals were similar. What is also important to note is that although Goulding and Gold pitched their article advocating buserelin as a surrogate for OVX the authors postulate that the differences identified for the two models may account for some steroidal protection in agonist treated rats. It is also possible that what Goulding and Gold had actually found was evidence of gonadotropins contributing to bone turnover but had overlooked their potential significance. Similarly Tobias and colleagues (1994) noted key differences between OVX and buserelin treatment on indices of trabecular bone turnover in rats; whereas 90 days post OVX produced up to $80 \%$ tibial cancellous bone loss, buserelin resulted in approximately $40 \%$ loss. In addition parameters reflecting changes in bone formation rate differed for the two models since buserelin treatment was not accompanied by increases in bone formation. Like Goulding and Gold, Tobias and colleagues suggested that the tool itself was to blame rather than providing a suggestion that gonadotropins in some way might be accountable. Importantly Yeh and colleagues (1996) subsequently revealed that an intact pituitary was necessary to trigger bone loss in response to estrogen withdrawal; whereas OVX resulted in marked bone loss, hypophysectomy in combination with OVX attenuated the osteopenic response. In light of the data that I had observed between Zoladex and OVX, I stated in my doctoral thesis that "These observations may support an important function for the gonadotropins in modulating the process of bone resorption." These data have since been published (Mansell et al 2007), but for a few years after obtaining my $\mathrm{PhD}$, bone biologists were reluctant to believe that gonadotropins had any role to play in skeletal metabolism following reports that LHRH agonists could cause osteopenia.

To further investigate the potential role of gonadotropins in skeletal development and morphology static histomorphometry and bone mineral density (BMD) were determined in mice nullizygous for the $\mathrm{LH}$ receptor (LuRKO) or mice overexpressing hCG. (Yarram et al 2003). Both groups exhibited skeletal phenotypes; male LuRKO mice had reduced bone mass for both femur and tibia whereas female hCG overexpressing mice had greatly elevated BMD at these sites. With regards to the latter model the circulating estrogen concentration was approximately double that of the wild type mice and would not have been sufficient to cause the large increase $(30 \%)$ in murine BMD given that only suprapharmacological levels of this steroid yield less than comparable BMD in mice (Samuels et al 1999). Importantly the increase in $\mathrm{BMD}$ reported for female $\mathrm{hCG}$ overexpressing mice could be prevented by OVX, thereby supporting a role of the ovary in generating the skeletal phenotype of these mice. One possible explanation however might be raised testosterone from hCG receptive thecal cells (Kumar 2005). Although the level of testosterone in the hCG overexpressing mice was elevated ( $\sim 6$-fold) the potential for this steroid to explain the bone phenotype requires corroboration.

As stated above, the research gleaned from the application of LHRH agonists to treat prostate cancer and endometriosis has raised concerns regarding their impact on the skeleton. Importantly the research gathered from the use of these agonists indicates that gonadotropins do not participate in bone tissue metabolism. However, the magnitude of bone 
loss appears to be small and "unlikely to be of any clinical relevance" (Fogelman 1992). Although there are studies identifying bone loss in response to LHRH agonist use there are also reports in which the risk of developing OP is no different to age-atched individuals in the community (eg, Peters et al 2001). Given that FSH/LH are greatly elevated at menopausal onset and that LHRH agonist administration does not mirror the skeletal changes observed for OVX it is possible that gonadotropins in some way contribute to bone catabolism.

\section{Adrenal hyperplasia in response to LH: Could LH promote bone loss via cortisol upregulation?}

A stark characteristic of the OVX rat/mouse is obesity; despite pair feeding with sham-operated controls, OVX animals always gain weight because of increases in intraabdominal fat. The increased fat and its distribution following OVX is likely linked to a Cushingoid state attributed to elevated glucocorticoids. Since the discovery of LH receptors in the adrenal gland and adrenal hyperfunction post OVX and the menopause (Kero et al 2000; Carlson 2007), it is tempting to hypothesize that raised LH post-OVX might drive bone catabolism via increased cortisol production. Excessive cortisol, as found for patients with Cushing's syndrome, increases the risk of developing OP because glucocorticoids diminish bone-forming osteoblast numbers (Manolagas 2000; Mancini et al 2004).

\section{Bone-resorbing osteoclasts are targets for FSH: the Mount Sinai Bone Program revelation}

The perimenopausal period is associated with the most rapid phase of bone loss (Randolph et al 2004; Sowers et al 2006) even in the face of higher-than-premenopausal estrogen levels but very high circulating FSH (Prior 1998). Devleta and colleagues (2004) have recently provided a compelling association between raised FSH and osteopenia in ammenorrheic women. Similarly Kawai and colleagues (2004) correlate reduced FSH with bone accrual in response to estrogen. Collectively these findings inspired the Mount Sinai Bone Program to investigate whether bone could be a target for FSH.

A combination of reverse transcription polymerase chain reaction (RT-PCR), flow cytometry, Western blotting, and immunocytochemistry revealed that human and murine osteoclasts, and their precursors, expressed FSH receptors (FSHR). Osteoclastogenesis occurred when both human and murine bone marrow precursors were co-treated with $\mathrm{FSH}$ and receptor activator for nuclear factor kappa $\mathrm{B}$ (NF-кB)-ligand (RANK-L), a factor central for osteoclast formation. Furthermore FSH stimulated bone resorption and triggered phosphorylation of Erk, Akt, and I $\mathrm{K}-\mathrm{B} \alpha$, effectors of the proresorptive actions of RANK-L. There are now good data supporting the expression of $\mathrm{G}_{\mathrm{i} 2 \alpha}$-coupled FSHR on osteoclasts and their precursors (Sun et al 2006).

In vivo, mice haploinsufficient for $\mathrm{FSH} \beta$ have raised bone mass precipitated by reduced osteoclast activity. Severe estrogen deficiency occurs in response to FSH $\beta$ or FSHR ablation yet mice nullizygous for either have preserved bone mass despite being estrogen-deficient. These striking findings indicate that FSH directly participates in the regulation of bone mass (Sun et al 2006; Zaidi et al 2007). Recall that a major local stimulus for driving bone resorption postmenopause is TNF- $\alpha$ and there are compelling studies putting TNF- $\alpha$ as a key mediator of bone loss in response to estrogen withdrawal (Pacifici 1998, 2008); mice nullizygous for TNF- $\alpha$ do not lose bone in response to OVX (Roggia et al 2001 ) and insensitivity to TNF- $\alpha$ protects against estrogen deficient osteopaenia (Ammann et al 1997; Kimble et al 1997; Charatcharoenwitthaya et al 2007). It is now known that this cytokine is mobilized by bone marrow precursors in response to FSH (Iqbal et al 2006).

\section{The low-density lipoprotein receptor-related protein 5 (LRP5) gene is linked to circulating FSH in normal postmenopausal women}

Low-density lipoprotein receptor-related protein 5 (LRP5) is a co-receptor for $\mathrm{Wnt} / \beta$-catenin signalling (He et al 2004). It is now known that LRP5 is required for osteoblast proliferation (Gong et al 2001; Kato et al 2002) and possibly the prevention of osteoblast apoptosis (Babij et al 2003). In a recent review of the literature (Mizuguchi et al 2004) it is becoming clear that LRP5/Wnt signaling is central for postnatal bone development and adult bone accrual making LRP5 an exciting candidate for further study in the context of musculoskeletal diseases, including osteoporosis and osteoarthritis.

Loss-of-function mutations in LRP5 result in osteoporosis-pseudoglioma syndrome (OPPG), an autosomal recessive disorder (Gong et al 2001). Conversely a gain-in-function mutation, for example a $\mathrm{G} 171 \mathrm{~V}$ point mutation, results in elevated bone mass, enhanced alkaline phosphatase activity 


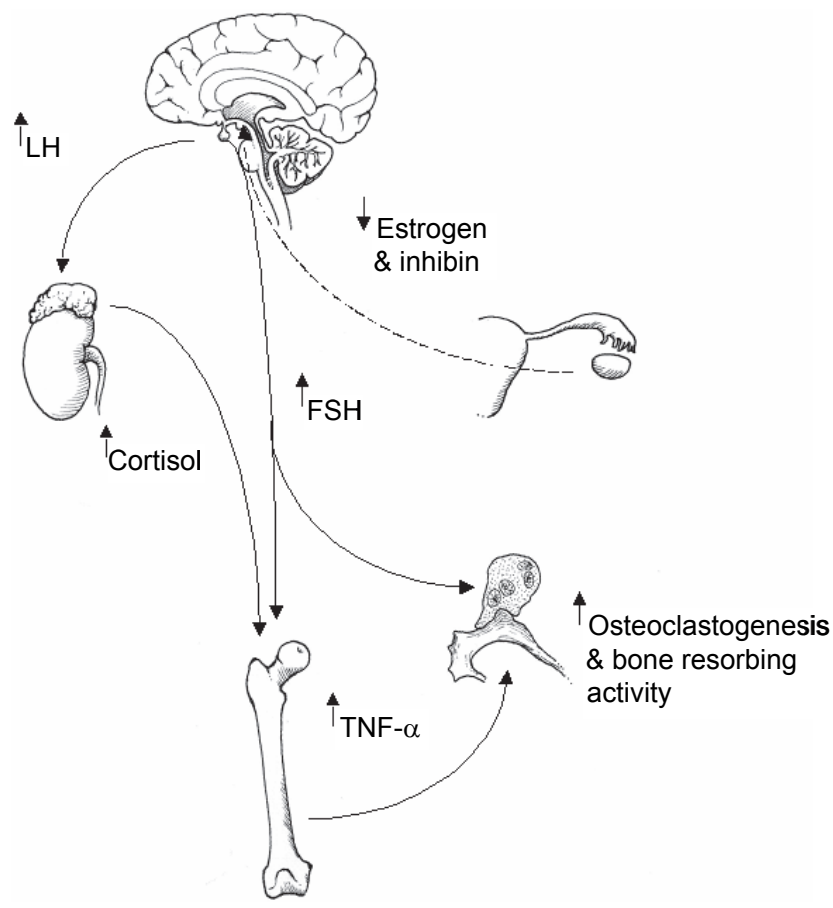

Figure I A summary of how follicle stimulating hormone $(\mathrm{FSH})$ and luteinizing hormone (LH) might co-operate in promoting bone catabolism postmenopause. Elevated levels of $\mathrm{LH}$ are known to induce adrenal cortex hyperfunction and resultant increases in circulating cortisol. It is postulated that increased cortisol in response to raised $\mathrm{LH}$ postmenopause impacts upon bone forming osteoblasts by inhibiting bone matrix synthesis through dampening osteoblast activity. In the long term the effect of raised cortisol will contribute to osteopaenia and the subsequent development of osteoporosis. Increasing levels of FSH could target at least two different compartments of bone tissue; the bone resorbing osteoclast population and bone marrow macrophage precursors. With regard to the former, FSH has been shown to directly activate osteoclastic resorption. With reference to the bone marrow, resident macrophage precursors are now known to mobilise tumor necrosis factor alpha (TNF- $\alpha$ ) in response to FSH. TNF- $\alpha$ is a key player in the demise of bone postmenopause through stimulating osteoclastic bone resorption. In this mode elevated $\mathrm{LH}$ and FSH co-operate in fuelling net bone loss thereby increasing the risk of developing osteoporosis.

and raised active osteoblast number (Babij et al 2003). Furthermore mutation analysis of families and patients has revealed at least 19 LRP5 sequence variants of which 6 are thought to result in a high bone mass phenotype (Van Wesenbeeck et al 2003).

It has recently been reported that $L R P 5$ is associated with circulating FSH in normal postmenopausal women (Zofkova et al 2007). A compelling association between serum FSH levels and a C/T (c.4037:A1330V) polymorphism in the LRP5 gene was identified whereas no relationship was found for LH, estrogen testosterone or their precursors. The link between FSH and LRP5 strengthens the postulation that LRP5 is implicated in the changes accompanying the menopause. In addition their relationship supports the concept of co-evolutionary mechanisms linking calcium homeostasis with reproductive biology.
Given the compelling association between the regulation of bone mass with LRP5 and the association between this co-receptor and circulating FSH, the dynamic relationship between LRP5 and FSH certainly warrants closer investigation into bone metabolism postmenopause.

\section{Concluding remarks}

The revelation made by Sun and colleagues (2006) that FSH is the chief miscreant for postmenopausal OP has sparked considerable debate amongst leading researchers in the field (Baron 2006; Martin and Gaddy 2006; Seibel et al 2006; Prior 2007); Seibel and colleagues (2006) postulate that the osteopaenic resistance in FSHR/ FSH $\beta$ nullizygous mice is attributed to raised testosterone in the face of elevated LH. Furthermore there are no reports of lower rates of bone loss for individuals with pituitary insufficiency compared to those with raised gonadotropins in response to natural or surgical menopause. In this regard Seibel and colleagues suggest that differences in the levels of sex steroids explain the skeletal phenotype reported by Sun and colleagues (2006). However it is important to recognize those clinical and natural endocrine events in which the estrogen-deficiency-osteoporosis model does not hold; importantly the rate of bone loss is greater during the perimenopause than during the first years postmenopause when estrogen levels are lower. Also, both estrogen and progesterone are required to negate premenopausal bone losses. Whilst Jerilynn Prior (2007) acknowledges that the estrogen-deficiency-osteoporosis model "faces considerable challenge" all are in agreement that much more research into the potential role of gonadotropins in skeletal physiology will have to be undertaken to displace it. Although we are far from a paradigm shift it is highly likely that our understanding of the skeletal response to estrogen deficiency will widen and with it changes in our approach to treating and preventing postmenopausal OP.

\section{Acknowledgments}

The author is indebted to Dr Alice May Roberts, University of Bristol, for the artwork presented in this review. The authors report no conflicts of interest in this work.

\section{References}

Albright F, Smith PH, Richardson AM. 1941. Postmenopausal osteoporosis-its clinical features. JAMA, 116:2465-74.

Ammann P, Rizzoli R, Bonjour JP, et al. 1997. Transgenic mice expressing soluble tumor necrosis factor-receptor are protected against bone loss caused by estrogen deficiency. J Clin Invest, 99:1699-703.

Babij P, Zhao W, Small C, et al. 2003. High bone mass in mice expressing a mutant LRP5 gene. J Bone Miner Res, 6:960-74. 
Bain SD, Bailey MC, Celino DL, et al. 1993. High-dose estrogen inhibits bone resorption and stimulates bone formation in the ovariectomized mouse. J Bone Miner Res, 8:435-42.

Baron R. 2006. FSH versus estrogen: who's guilty of breaking bones? Cell Metab, 3:302-5.

Carlson HE. 2007. Human adrenal cortex hyperfunction due to LH/hCG. Mol Cell Endocrinol, 269:46-50.

Charatcharoenwitthaya N, Khosla S, Atkinsn EJ, et al. 2007. Effect of blockade of tumor necrosis factor-alpha and interleukin-1 action on bone resorption in early postmenopausal women. J Bone Miner Res, 22:724-9.

Devleta B, Adem B, Senada S. 2004. Hypergonadotropic amenorrhea and bone density: new approach to an old problem. J Bone Miner Res, $22: 360-4$.

Eriksen EF, Colward DS, Bery NJ, et al. 1988. Evidence of oestrogen receptors in normal human osteoblast-like cells. Science, 241:84.

Ernst M, Health JK, Rodan GA. 1989. Estradiol effects on proliferation, messenger ribonucleic acid for collagen and insulin-like growth factor I, and parathyroid hormone-stimulated adenylate cyclase activity in osteoblastic cells from calvariae and long bones. Endocrinology, 125:825-33.

Fogelman MD. 1992. Gonadotropin-releasing hormone agonists and the skeleton. Fertil Steril, 57:715-24.

Gong Y, Slee RB, Fukai N, et al. 2001. LDL receptor-related protein 5 (LRP5) affects bone accrual and eye development. Cell, 107:513-23.

Goulding A, Gold E. 1989. A new way to induce oestrogen deficient osteopaenia in the rat: comparison of the effects of surgical ovariectomy and administration of the LHRH agonist buserelin on bone resorption and composition. J Endocrinol, 121:293-8.

Gray TK. 1989. Oestrogens and the skeleton: cellular and molecular mechanisms. J Steroid Biochem, 34:285-7.

He X, Semenov M, Tamai K, et al. 2004. LDL receptor related protein 5 and 6 in Wnt/beta-catenin signalling: arrows point the way. Development, 131:1663-77.

Iqbal JL, Sun L, Kumar TR, et al. 2006. Follicle stimulating hormone stimulates TNF production from immune cells to enhance osteoblast and osteoclast formation. Proc Natl Acad Sci US A, 103:14925-30.

Kato M, Patel MS, Levasseur R, et al. 2002. Cbfa-1 independent decrease in osteoblast proliferation,osteopaenia, and persistent embryonic eye vascularisation in mice deficient in LRP5, a Wnt coreceptor. J Cell Biol, 157:303-14.

Kawai H, Furuhashi M, Suganuma N. 2004. serum follicle stimulating hormone level is a predictor of bone mineral density in patients with hormone replacement therapy. Arch Gynecol Obstet, 269:192-5.

Keeting PE, Scott RE, Colward DS, et al. 1991. Lack of a direct effect of oestrogen on proliferation and differentiation of normal human osteoblast-like cells. J Bone Miner Res, 6:297-304.

Kero J, Poutanen M, Zhang F-P, et al. 2000. Elevated luteinizing hormone induces expression of its receptor and promotes steroidogenesis in the adrenal cortex. J Clin Invest, 105:633-41.

Kimble R, Bain S, Pacifici R. 1997. The functional block of TNF but nor of IL-6 prevents bone loss in ovariectomized mice. J Bone Miner Res, 12:935-41.

Komm BS, Terpening CM, Binz DJ, et al. 1988. Estrogen binding, receptor mRNA and biologic response in osteoblast-like osteosarcoma cells. Science, 241:81-4.

Kumar TR. 2005. What have we learned about gonadotropin function from gonadotropin subunit and receptor knockout mice? Reproduction, 130:293-302

Lindberg MK, Alatalo SL, Halleen JM, et al. 2001. Estrogen receptor specificity in the regulation of the skeleton in female mice. JEndocrinol, 171:229-36.

Lindsay R. 2004. Hormones and bone health in postmenopausal women. Endocrine, 24:223-30.

Mahonen A, Jukkola A, Risteli L, et al. 1998. Type I procollagen synthesis is regulated by steroids and related hormones in human osteosarcoma cells. J Cell Biochem, 68:151-63.
Mancini T, Doga M, Mazziotti G, et al. 2004. Cushing's syndrome and bone. Pituitary, 7:243-6.

Manolagas SC. 2000. Birth and death of bone cells: basic regulatory mechanisms and implications for the pathogenesis and treatment of osteoporosis. Endocr Rev, 21:115-37.

Mansell JP, Bailey AJ, Yarram SJ. 2007. Could bone tissue be a target for luteinizing hormone/chorionic gonadotropin? Mol Cell Endocrinol, 269:99-106.

Martin JT, Gaddy D. 2006. Bone loss goes beyond estrogen. Nature Med, 12:612-3.

McCauley LK, Tözüm TF, Rosol TJ. 2002. Estrogen receptors in skeletal metabolism: lessons from genetically modified models of receptor function. Crit Rev Eukaryot Gene Expr, 12:89-100.

McOsker JE, Li XJ. 1991. Use of rectilinear single photon absorptiometry to evaluate bone mass changes in rats. Scanning Microscopy International, Chicago. Cell Mater Suppl 1:93-104.

Medvei VC. 1982. A history of endocrinology. Norwell, MA: Kluwer Academic Publishers.

Mizuguchi T, Furuta I, Watanabe Y, et al. 2004. LRP5, low densitylipoprotein-receptor-related protein 5 , is a determinant for bone mineral density. J Hum Genet, 49:80-6.

Nakamura T, Imai Y, Matsumoto T, et al. 2007. Estrogen prevents bone loss via estrogen receptor alpha and induction of Fas ligand in osteoclasts. Cell, 130:811-23

Pacifici R. 1998. Editorial: cytokines, estrogen, and postmenopausal osteoporosis - the second decade. Endocrinology, 139:2659-61.

Pacifici R. 2000. Estrogen deficiency, T cells and bone loss. Cell Immunol, 252(1-2):68-80.

Peters JL, Fairney A, Kyd P, et al. 2001. Bone loss associated with the use of LHRH agonists in prostate cancer. Prostate Cancer Prostatic Dis, 4:161-6.

Prior JC. 1998. Perimenopause: the complex endocrinology of the menopausal transition. Endocrinol Rev, 19:397-428.

Prior JC. 2007. FSH and bone-important physiology or not? Trends Mol Med, 13:1-3.

Randolph JF, Sowers M, Bondarenko IV, et al. 2004. Change in estradiol and follicle stimulating hormone across the early menopausal transition: effects of ethnicity and age. J Clin Endocrinol Metab, 89:1555-61.

Robinson JA, Harris SA, Riggs BL, et al. 1997. Estrogen regulation of human osteoblastic cell proliferation and differentiation. Endocrinology, 138:2919-27.

Rodan GA. 1991. Mechanical loading, oestrogen deficiency, and the coupling of bone formation to bone resorption. J Bone Miner Res, 6:527-9.

Roggia C, Gao Y, Genci S, et al. 2001. Up-regulation of TNF-producing $\mathrm{T}$ cells in the bone marrow: a key mechanism by which estrogen deficiency induces bone loss in vivo. Proc Natl Acad Sci U S A, 98:13960-5.

Samuels A, Perry MJ, Tobias JH. 1999. High-dose estrogen induces de novo medullary bone formation in female mice. J Bone Miner Res, 14:178-86.

Saville PD. 1969. Changes in skeletal mass and fragility with castration in the rat: a model of osteoporosis. J Am Geriatrics Soc, 17:155-64.

Seibel MJ, Dunstan CR, Zhou H, et al. 2006. Sex steroids, not FSH, influence bone mass. Cell, 127:1079.

Sowers MR, Jannausch M, McConnell D, et al. 2006. Hormone predictors of bone mineral density changes during the menopausal transition. J Clin Endocrinol Metab, 91:1261-7.

Stevenson JC. 2005. Justification for the use of HRT in the long-term prevention of osteoporosis. Maturitas, 51:113-26.

Sun L, Peng Y, Sharrow AC, et al. 2006. FSH directly regulates bone mass. Cell, 125:247-60.

Tobias JH, Chambers TJ, Gallagher A. 1994. Effect of administration and subsequent cessation of buserelin on cancellous bone of female rats. J Bone Miner Res, 9:1919-25.

Turner RT, Riggs BL, Spelsberg TC. 1994. Skeletal effects of estrogen. Endocrinol Rev, 15:275-300. 
Turner RT. 1999. Mice, estrogen, and postmenopausal osteoporosis. J Bone Miner Res, 14:187-91.

Van Wesenbeeck L, Cleiren E, Gram J, et al. 2003. Six novel missense mutations in the LDL receptor-related protein 5 (LRP5) gene in different conditions with an increased bone density. Am J Hum Genet, 72:763-71.

Ward JA, Furr BJ, Valcaccia B, et al. 1989. Prolonged suppression of rat testis function by a depot formulation of Zoladex, a GnRH agonist. $J$ Androl, 10:478-86.

Westerlind KC, Wakley GK, Evans GL, et al. 1993. Estrogen does not increase bone formation in growing rats. Endocrinology, 133:2924-34.

Windahl SH, Andersson G, Gustafsson JA. 2002. Elucidation of estrogen receptor function in bone with the use of mouse models. Trends Endocrinol Metab, 13:195-200.
Wronski TJ, Yen CF. 1991. The ovariectomised rat as an animal model for postmenopausal bone loss. Scanning Microscopy International, Chicago. Cells Mater Suppl, 1:69-74.

Yarram SJ, Perry MJ, Christopher TJ, et al. 2003. Luteinizing hormone receptor knockout (LuRKO) mice and transgenic human chorionic gonadotropin (hCG) overexpressing mice $(\mathrm{hCG} \alpha \beta+)$ have bone phenotypes. Endocrinology, 144:3555-64.

Yeh JK, Chen MM, Aloia JF. 1996. Ovariectomy-induced high turnover in cortical bone is dependent on pituitary hormone in rats. Bone, $18: 443-50$.

Zaidi M, Blair HC, Iqbal J, et al. 2007. Proresorptive actions of FSH and bone loss. Ann NY Acad Sci, 1116:376-82.

Zofkova I, Hill M, Zajickova K. 2007. Association of C/T polymorphism in the LRP5 gene with circulating follicle stimulating hormone in Caucasian postmenopausal women. Physiol Res, 56:735-9. 
